\title{
A new strategy using autologous dendritic cells and lymphokine- activated killer cells for cancer immunotherapy: Efficient maturation of DCs by co-culture with LAK cells in vitro
}

\author{
YUTARO YANO $^{1 *}$, YUJI UEDA ${ }^{1 *}$, TSUYOHI ITOH ${ }^{1 *}$, NOBUAKI FUJI $^{1}$, KAORI OKUGAWA $^{1}$, \\ KEI NAITO ${ }^{1}$, KENICHIRO IMURA ${ }^{1}$, JUNJI KOHARA ${ }^{1}$, TAKASHI HAYASHI ${ }^{2}$, KAZUKI NAKANE $^{3}$, \\ YUKO MATSUURA $^{3}$, KEIICHI KAWAI ${ }^{3}$ and HISAKAZU YAMAGISHI ${ }^{1}$ \\ ${ }^{1}$ Division of Digestive Surgery, Department of Surgery, Kyoto Prefectural University of Medicine, 465 Kajii-cho, \\ Kawaramachi-Hirokoji, Kamigyo-ku, Kyoto 602-8566; ${ }^{2}$ Department of Surgery, Takeda Hospital, \\ Shiokoji-cho 841-5, Shimogyo-ku, Kyoto 600-8558; ${ }^{3}$ Bio-health Center, Takeda Hospital, \\ Keiaikosan-Kyoto BLDG, Kankoboko-cho 87, Shimogyo-ku, Kyoto 600-8009, Japan
}

Received January 27, 2006; Accepted March 20, 2006

\begin{abstract}
Among a variety of antigen presenting cells (APCs), accumulating results support that the mature dendritic cell (DC) has the potential to induce efficient cytotoxic $\mathrm{T}$ lymphocyte (CTL) responses in the context of peptide-based immunotherapy. DCs have been known to assume the mature form by signaling through the CD40-CD40 ligand (CD40L) interaction, which may be provided by activated $\mathrm{CD} 4^{+} \mathrm{T}$ cells expressing abundant CD40L molecules on their surfaces. Here, we report that DCs generated from peripheral blood monocytes obtained from patients with advanced cancer exhibit a mature phenotype after co-culturing with autologous lymphokine-activated killer (LAK) cells generated by the stimulation of peripheral blood mononuclear cells with anti-CD3 monoclonal antibody (mAb) and interleukin (IL)-2. Part of this process appeared to be dependent on the expression of CD40L on the surface of LAK cells, although it was also suggested that some other humoral factors produced by LAK cells may be involved in this effect as well. DCs derived from the donors, of which LAK cells demonstrated a higher Th1/Th2 ratio upon activation determined by the intracellular detection of interferon- $\gamma$ and IL-4, showed more efficient maturation upon co-culture with LAK cells than DCs from donors with a low Th1/Th2 ratio.
\end{abstract}

Correspondence to: Dr Yuji Ueda, Division of Digestive Surgery, Department of Surgery, Kyoto Prefectural University of Medicine, 465 Kajii-cho, Kawaramachi-Hirokoji, Kamigyo-ku, Kyoto 6028566, Japan

E-mail: yueda@koto.kpu-m.ac.jp

${ }^{*}$ Contributed equally

Key words: dendritic cell, lymphokine-activated killer cell, CD40CD40 ligand interaction, cytokine, cancer immunotherapy
Importantly, these matured DCs induced a two-times stronger antigen-presenting capacity measured by an allo-reactive mixed lymphocytes reaction assay as compared to immature DCs. These results imply the use of the combination of DCs and LAK cells for immunotherapy against cancer.

\section{Introduction}

The dendritic cell (DC) is the most potent antigen-presenting cell (APC) and is used as an adjuvant for a number of clinical studies of active immunotherapy for cancer. Although the DC is considered to be a powerful tool to immunize patients being potentially under an immunosuppressive status caused by cancer, the vaccine protocol needs to be well designed in terms of the cell culture environment and the cell source from which DCs are prepared, as well as the maturation status of DCs to elicit efficient anti-tumor responses. Specifically, DCs that have a myeloid origin, including Langerhans cells as well as interstitial DCs, play a critical role in inducing cellular immune responses as acquired immunity, whereas plasmacytoid DCs are involved more in innate immunity (1). So far, human peripheral blood monocyte-derived myeloid DCs have been most widely used for clinical trials, perhaps because of their accessibility (2). Importantly, accumulating results indicate that the mature DC is more potent for inducing an efficient immune response, which may lead to tumor eradication, than immature DCs in the context of a peptide-based vaccine strategy, whereas immature DCs may potentially induce immune tolerance (3-5).

In many studies, monocyte-derived mature DCs are generated in the culture in the presence of interleukin (IL)-4 and granulocyte/macrophage colony-stimulating factor (GM-CSF), followed by additional culture in the presence of several cytokines that allow DCs to differentiate into the matured form. Inflammatory cytokines such as IL-1ß, IL-6, and tumor necrosis factor (TNF)- $\alpha$ and prostaglandin $\mathrm{E}_{2}$ are commonly used for this maturation step $(6,7)$. However, the more exogenous cytokines are used, the more expensive and labor-intensive the protocol may become. Recently, as a novel way to prepare 
mature DCs without exogenous cytokines, a new strategy utilizing activated $\mathrm{T}$ cells by phytohemagglutinin and ionomycin for DC maturation has been proposed by showing that the co-culture of these two types of cells resulted in the maturation of DC in terms of the up-regulation of CD83 expression and the production of IL-12 in the in vitro culture system (8). This strategy was based on evidence that the DC is known to differentiate into the matured form by signaling through a CD40-CD40 ligand (CD40L) interaction, which may be provided by activated $\mathrm{CD}^{+} \mathrm{T}$ cells to have a more potent antigen-presenting capacity (9-11). On the other hand, lymphokine-activated killer (LAK) cells have been studied for use as a modality of tumor immunotherapy for many years. Previous studies have indicated that LAK cells induce an anti-tumor response by perforin-mediated cytolytic activity, as well as the cytokines they produce $(12,13)$. Although these effects are not truly antigen-specific, their applicability for use in immunotherapy remains promising, especially for tumors that lack the expression of MHC-class I molecules on their surfaces.

In this study, we hypothesized that LAK cells induced by anti-CD3 monoclonal antibody (mAb) in the presence of IL-2, which supposedly express abundant CD40L on their surfaces, could stimulate autologous immature DCs and allow them to differentiate into the matured form. We also investigated the capacity of the DCs activated in this protocol as to their ability to present antigens to T cells in an allogeneic mixed lymphocyte response (MLR). To explore the possibility of applying this strategy in a clinical setting, we mostly focused on the experiments using the materials derived from patients with advanced cancer.

\section{Materials and methods}

Patients and cells. Peripheral blood mononuclear cells (PBMCs) were isolated from patients with advanced cancer after obtaining written informed consent using Ficoll-Paque PLUS (Amersham-Pharmacia, Uppsala, Sweden) density gradient centrifugation. All patients had received surgery and chemotherapy prior to participation in this study, and at least four weeks had passed at the time of collection of PBMCs. The PBMCs were suspended in $25 \%$ human serum albumin (Kaketsuken Inc., Tokyo, Japan) with CP-1 (Kyokuto, Kyoto, Japan) and hydroxyethyl starch at a content of $5 \times 10^{7}$ cells $/ \mathrm{ml}$, and divided into vials, each containing $2 \mathrm{ml}$ of the suspension. All vials were stored at $-80^{\circ} \mathrm{C}$ until use.

In vitro generation of DCs. PBMCs were allowed to adhere in a 6-well plate at a density of $1 \times 10^{7}$ cells/well for $1 \mathrm{~h}$ at $37^{\circ} \mathrm{C}$ in RPMI-1640 (Nikken, Kyoto, Japan). Adherent cells were then cultured in $4 \mathrm{ml}$ of RPMI-1640 supplemented with $2 \%$ heat-inactivated pooled human $\mathrm{AB}$ serum, $50 \mathrm{ng} / \mathrm{ml}$ of human GM-CSF (PeproTech House, London, UK) and $50 \mathrm{ng} /$ $\mathrm{ml}$ of human IL-4 (PeproTech House) for 6 days. Cells were incubated at $37^{\circ} \mathrm{C}$ in $5 \% \mathrm{CO}_{2}$.

In vitro generation of $L A K$ cells. PBMCs were seeded in a 24-well plate coated with anti-CD3 $\mathrm{mAb}$ at a concentration of $2 \times 10^{6}$ cells/well in $2 \mathrm{ml}$ of RPMI-1640 supplemented with $5 \%$ heat-inactivated pooled human $\mathrm{AB}$ serum and $100 \mathrm{U} / \mathrm{ml}$ of human IL-2 (Shionogi, Osaka, Japan) for 7 days. Cells were incubated at $37^{\circ} \mathrm{C}$ in $5 \% \mathrm{CO}_{2}$ and half the medium was changed every 3 days.

Activation of DCs with LAK cells. DCs were co-cultured with LAK cells harvested on day 7 at a ratio of $1: 1\left(1 \times 10^{7}\right.$ cells in total/well) for $24 \mathrm{~h}$. Cell insert with a pore size of $0.4 \mu \mathrm{m}$ (NUNC, Rochester, NY) was used in the culture to prevent physical cellular contact in some experiments. For the blocking of CD40-CD40L signaling, LAK cells were pre-incubated with anti-CD40L mAb (TRAP-1, $40 \mu \mathrm{g} / \mathrm{ml}$, BD Biosciences, Heidelberg, Germany) for $90 \mathrm{~min}$ before co-culturing with DCs.

Phenotypic analyses of DCs and LAK cells. Flow cytometric analysis was performed by FACScalibur (Becton-Dickinson, San Diego, CA) using CellQuest software (Becton-Dickinson). DCs were analyzed for the phenotype markers with the following mAbs: anti-CD14, anti-CD40 (Pharmingen, San Diego, CA), anti-CD80, anti-CD83, anti-CD86 (Immunotech, Marceille, France). Monoclonal Abs for CD3, CD4, CD8 and CD40L (Pharmingen) were also used for the phenotypic analysis of LAK cells.

Detection of intracellular cytokine production by LAK cells. For the detection of the intracellular cytokine productions, LAK cells were stimulated with PMA $(20 \mathrm{ng} / \mathrm{ml})$ and ionomycin $(1 \mu \mathrm{g} / \mathrm{ml})$ for $4 \mathrm{~h}$ in the presence of Golgistop ${ }^{\mathrm{TM}}$ (BectonDickinson) and treated with Cytofix/CytoPerm ${ }^{\mathrm{TM}}$ (BectonDickinson), and then were stained with PE-conjugated antiIL-4 mAb and FITC-conjugated anti-interferon (IFN)- $\gamma \mathrm{mAb}$ for $30 \mathrm{~min}$ at room temperature. LAK cells producing intracellular IL- 4 and IFN- $\gamma$ were determined by flow cytometry (FACScalibur). All mAbs and isotype-control IgG were purchased from Becton-Dickinson.

$T$ cell proliferation assay. Allo-MLR was performed to evaluate the antigen-presenting capacity of DCs. Responder $\mathrm{T}$ cells were used at $6 \times 10^{5}$ cells per well in a 96 -well plate. The enrichment of DCs co-cultured with LAK cells was performed using anti-HLA-DR MACS beads (Miltenyi, Bergisch Gladbach, Germany) according to the manufacturer's instruction. DCs as stimulator cells were added to $2 \times 10^{4}$ cells (stimulator:responder $=1: 30)$ after irradiation $(25 \mathrm{~Gy})$ and cultures were set up in triplicate and maintained at $37^{\circ} \mathrm{C}$ in $5 \% \mathrm{CO}_{2}$ for 4 days. Cultures were then added $1.0 \mu \mathrm{Ci} /$ well to ${ }^{3} \mathrm{H}$-thymidine $12 \mathrm{~h}$ before harvesting and ${ }^{3} \mathrm{H}$-thymidine incorporation was measured by scintillation counting.

\section{Results}

LAK cells generated from PBMCs derived from patients with advanced cancer express various amounts of CD40L on their surfaces. First, we investigated the surface expression of CD40L on the lymphocytes activated with anti-CD3 mAb in the presence of IL-2. PBMCs derived from patients with several types of advanced cancer including 4 colorectal and 2 lung cancers, as shown in Table I, were put in the culture and activated in vitro, as indicated in Materials and methods. All of the patients enrolled in this study had completed prior 
Table I. Patient characteristics and CD40L expression on lymphokine-activated PBMCs.

\begin{tabular}{lcllll}
\hline Patient & Age/Gender & Cancer type & \multicolumn{1}{c}{ Metastasis } & CD40L expression & Prior therapy $^{\mathrm{b}}$ \\
\hline 1 & $56 / \mathrm{M}$ & Rectal & Liver metastasis & 21.2 & $\mathrm{~S}, \mathrm{C}$ \\
2 & 69/M & Lung & Pleural dissemination & 24.2 & $\mathrm{~S}, \mathrm{C}$ \\
3 & $56 / \mathrm{M}$ & Colon & Liver metastasis & 10.7 & $\mathrm{~S}, \mathrm{C}$ \\
4 & $42 / \mathrm{F}$ & Colon & Liver metastasis & 1.32 & $\mathrm{~S}, \mathrm{C}$ \\
5 & $54 / \mathrm{F}$ & Colon & Liver, bone, lung metastasis & 0.76 & $\mathrm{~S}, \mathrm{C}$ \\
6 & $39 / \mathrm{M}$ & Lung & Bone metastasis & 0.71 & $\mathrm{~S}, \mathrm{C}$ \\
\hline
\end{tabular}

a\% CD40L-positive cells in PBMCs activated with anti-CD3 monoclonal antibody and interleukin-2 in vitro. ${ }^{\text {b }}$, surgery; C, chemotherapy.

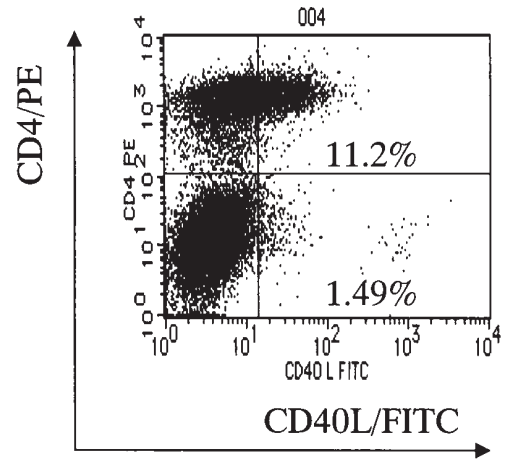

Figure 1 . The majority of the cells positive for CD40L are $\mathrm{CD} 4^{+} \mathrm{T}$ cells. Nonadherent PBMCs were cultured on a plate coated with anti-CD3 mAb in the presence of IL-2 for 7 days and then stained with anti-CD40L mAb and antiCD4 mAb. A dot plot of the cells gated on live cells based on the signals detected from forward scatter and side scatter is depicted.

treatment such as surgery and chemotherapy at least four weeks previously. Cells were determined for the surface expression of CD40L by flow cytometric analysis on various days between 1 and 11 after the initiation of the culture. We found that cells reached their maximum level of CD40L expression by day 5 and were able to maintain this expression until day 9 (data not shown) without significant decrease. Therefore, we decided to harvest the LAK cells on day 7 and used them for subsequent experiments as an optimal condition. As shown in Table I, $>10 \%$ of the LAK cells showed CD40L positivity in three (Donor nos. 1-3) out of six patients. One representative result from FACS analyses demonstrating a considerable amount of CD40L-positive LAK cells is shown in Fig. 1. Most of the cells (86\%) that express CD40L were positive for CD4 as well, whereas few of them were positive for CD8 (data not shown). Since we observed substantial variation regarding CD40L expression on LAK cells from donor to donor, several phenotypic characteristics of PBMCs before culture were examined to see if there was any correlation between the levels of CD40L expression and phenotypic markers of PBMCs. Consistent with the finding that CD40L positive cells were mainly observed in the CD4+ $\mathrm{T}$ cell population (Fig. 1), patients with a high CD4/CD8 ratio (nos. 1,2) $(>1.0)$ of PBMCs before culture showed a significantly higher level of $\mathrm{CD} 40 \mathrm{~L}$ expression ( $\mathrm{p}<0.03$, unpaired $\mathrm{t}$-tests) after

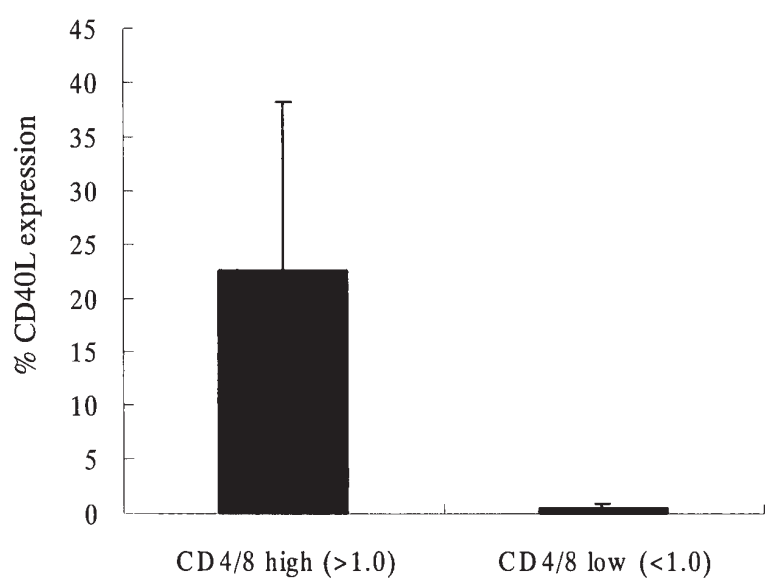

Figure 2. Higher expression of CD40L on LAK cells are observed in patients with $>1.0$ of CD4/CD8 ratio in PBMCs before the induction of LAK cells. The surface phenotype was assessed by FACS analysis using anti-CD4 and anti-CD8 mAbs, and the ratios of \% CD4/\% CD8 of PBMCs from each donor were calculated. Percentages of CD40L-positive cells were determined by FACS analyses of LAK cells after stimulation with anti-CD3 mAb and IL-2. Data represent the mean \pm SD.

activation than patients with a low CD4/CD8 ratio (nos. 3-6) (Fig. 2).

CD4OL-positive LAK cells promote phenotypical and functional maturation of DCs in vitro. Next, we examined if the coculture with autologous LAK cells promotes the maturation of DCs generated from peripheral blood monocytes. DCs were determined for their expression of CD80, CD83 and CD86 as the maturation markers before and after co-culturing with LAK cells for $24 \mathrm{~h}$. The culture conditions of DCs and LAK cells were determined according to the results from preliminary experiments so that the surface expression of CD86 could become maximum level. The results from donor no. 1 demonstrated that the expression of these maturation markers on DCs was up-regulated after co-culture (Fig. 3a). Interestingly, two patients (nos. 1 and 2, both of whom, showed $>20 \%$ of $\mathrm{CD}_{40 \mathrm{~L}^{+}}$cells in LAK cells) out of three with high expression of CD40L showed $>50 \%$ of $\mathrm{CD}^{2} 0^{+}$and $\mathrm{CD} 83^{+}$on DCs after co-culture, whereas all of the patients with low expression of CD40L showed levels of CD83 expression $<10 \%$ (Fig. 3b). These results support our hypothesis that DCs may be activated 
a

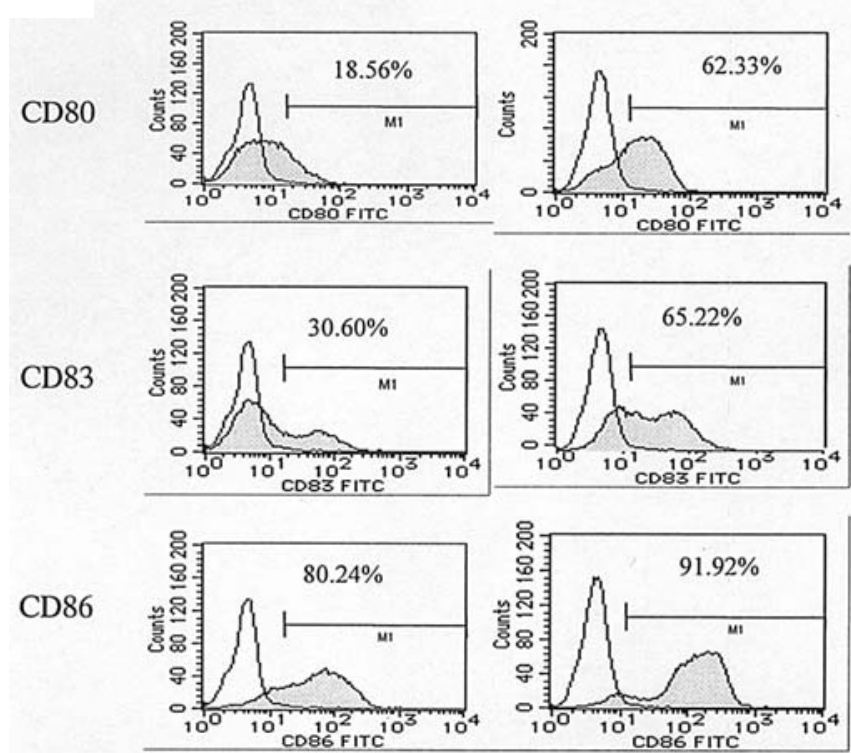

b
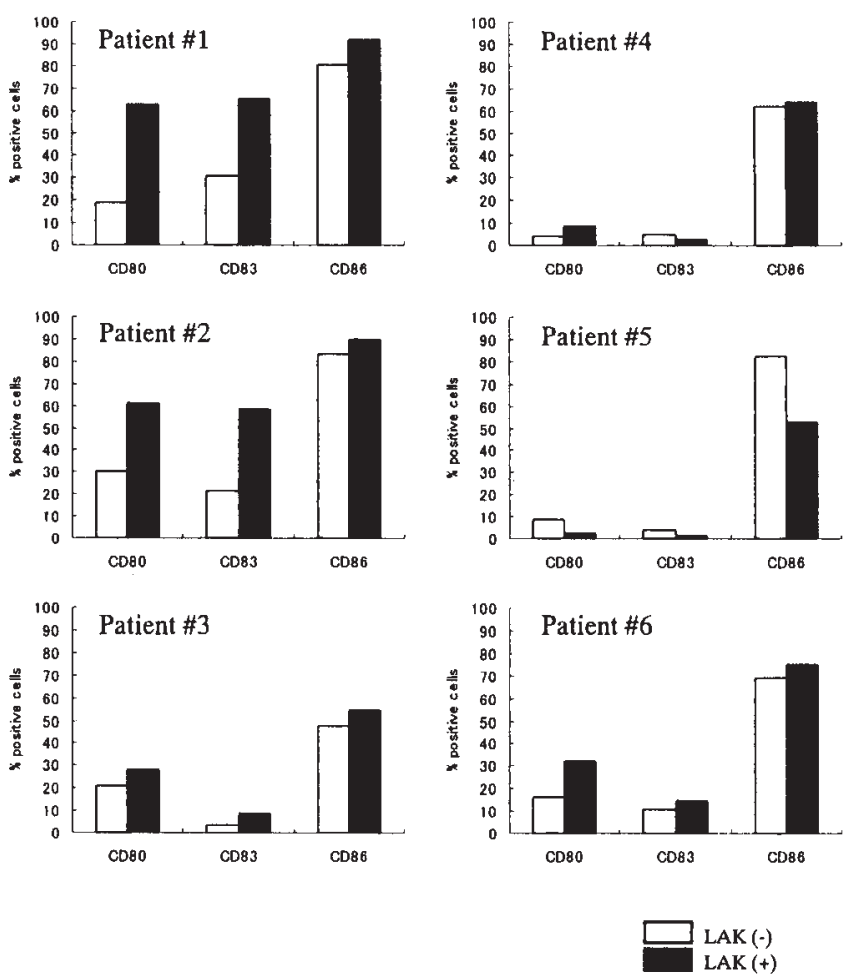

Figure 3. Maturation markers for DCs are up-regulated after the co-culture with LAK cells positive but not negative for CD40L. DCs were co-cultured with or without autologous LAK cells for $24 \mathrm{~h}$ and then stained with either anti-CD80, anti-CD83 or anti-CD86 mAbs for the phenotypic analysis by FACS. (a) The representative data obtained from patient no. 1 are shown. A shaded histogram was acquired from cells stained with each mAb of interest, and an open histogram was acquired from cells stained with the isotype control IgG. The numbers represented in each histogram indicate the \% positive cells for each molecule detected by mAb. (b) Percent positive cells for each mAb after the co-culture with or without LAK cells in all six patients are shown.

by LAK cells, possibly through the interaction between CD40 and CD40L. To characterize the DCs matured with LAK cells in terms of their function, an allo-MLR experiment was conducted. As shown in Fig. 4, the proliferation of T cells was approximately doubled when DCs matured with LAK

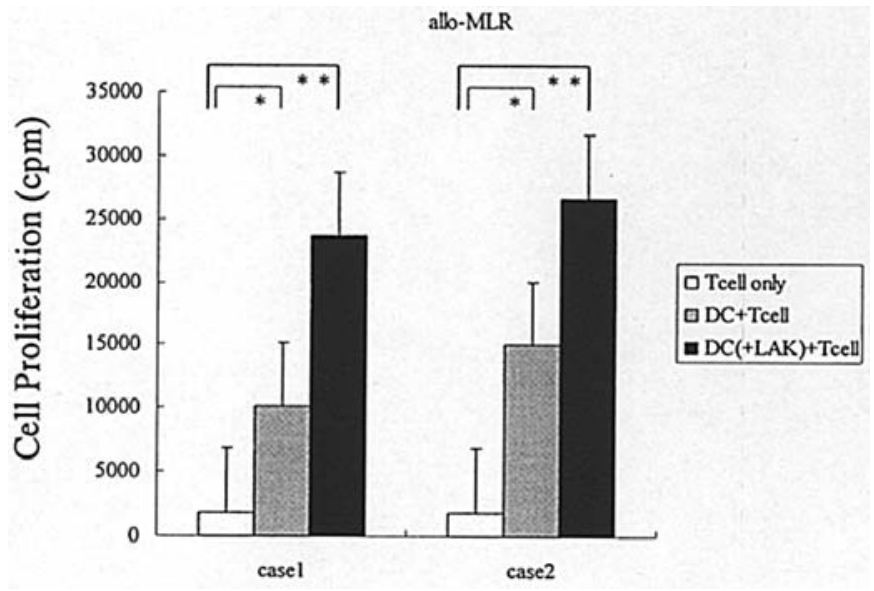

Figure 4. DCs activated by autologous LAK cells have higher activity in allo-stimulating responses. Allogeneic T cells were stimulated with DCs that had been cultured with or without LAK cells for 4 days. $1.0 \mu \mathrm{Ci} /$ well of ${ }^{3} \mathrm{H}$-thymidine was added to the culture before the final $12 \mathrm{~h}$ and ${ }^{3} \mathrm{H}$-thymidine incorporation was measured by scintillation counting to determine $\mathrm{T}$ cell proliferation activity. Data obtained from one representative result out of three repeated experiments are shown as an average from triplicated wells $\left(\right.$ mean $\left.\pm \mathrm{SD} ;{ }^{*} \mathrm{p}<0.03 ;{ }^{* *} \mathrm{p}<0.01\right)$.

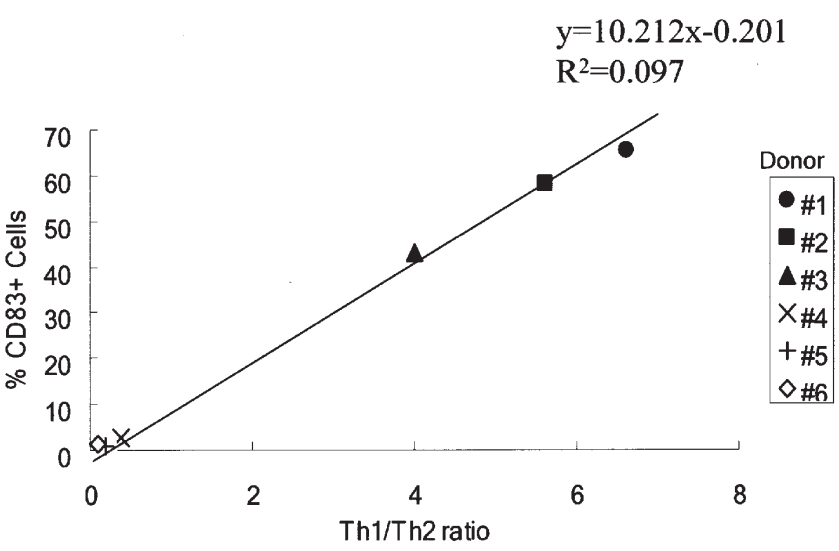

Figure 5. The relationship between the Th1/Th2 ratio of cytokine-producing profiles in LAK cells used for activation of DCs and the \% expression of CD83 on activated DCs. DCs were analyzed for their expression of CD83 on the surface after activation with autologous LAK cells. Data were plotted for the \% expression of CD83 on DCs on the Y-axis and Th1/Th2 ratio of LAK cells based on the intracellular IFN- $\gamma$ and IL-4 production profiles on the $\mathrm{X}$-axis.

cells were used as the APCs as compared to immature DCs. Since there have been some reports showing that DCs that had been cultured in a Th-1-oriented environment seemed to be more capable in antigen-presentation than those exposed to the Th-2 condition (14), we next examined whether there is any correlation between the Th1/2 ratio of LAK cells and the level of the expression of maturation markers on DCs in our culture system. Intracellular cytokine productions of IFN- $\gamma$ and IL- 4 in LAK cells were determined by FACS to assess the Th1/2 ratio of LAK cells. As expected, there was a high correlation between the efficiency of DC maturation and the Th1/Th2 ratio of LAK cells (Fig. 5).

The maturation of DCs by co-culturing with LAK cells is largely dependent on the interaction between CD4O and 
a

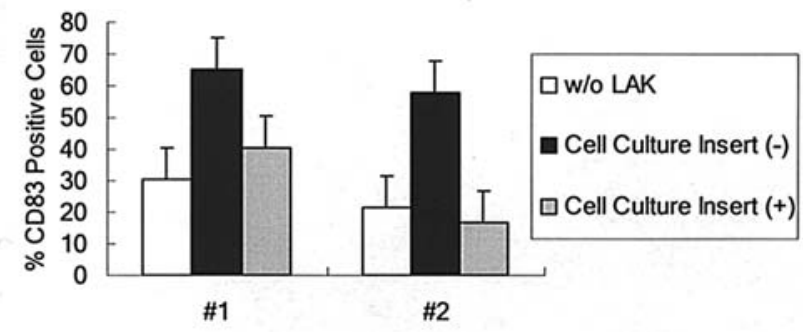

b

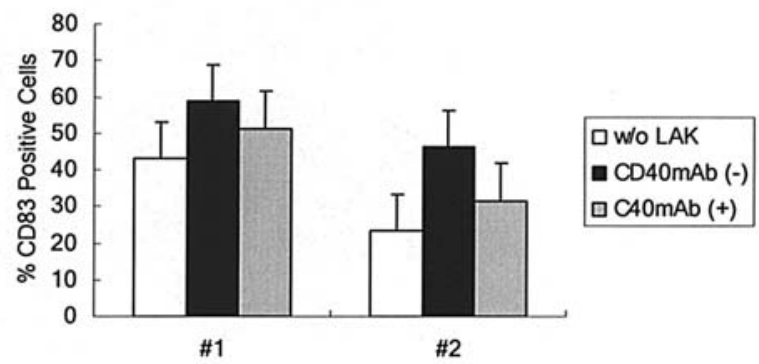

Figure 6. The maturation effects of co-culturing with autologous LAK cells on DCs are abolished by the inhibition of cell-to-cell contact as well as the blocking of CD40-CD40L interaction by monoclonal antibody specific for CD40L. DCs were co-cultured with autologous LAK cells with or without the presence of cell culture insert (a) or the presence of anti-CD40L mAb (b). Percentage of CD83 positive cells in DCs are shown in the figure. The data obtained from one representative result out of three repeated experiments are shown.

CD40L. To investigate the significance of CD40L expression on LAK cells on the maturation of DCs, we used a cell insert system to prevent the direct cell-to-cell contact between LAK cells and DCs. As shown in Fig. 6a, the up-regulation of CD83 on DCs was markedly, if not totally, blocked by the use of the cell insert. We then looked into the effect of the signaling specifically through CD40-40L on the maturation of DCs by the incubation of DCs and LAK cells pre-incubated with anti-CD40L mAb to block its signaling (Fig. 6b). The maturation effect on DCs by LAK cells was inhibited by 45 and $64 \%$ in patients no. 1 and 2, respectively.

\section{Discussion}

Here, we demonstrated that the co-culture of DCs with autologous LAK cells generated by anti-CD3 mAb and IL-2 promoted the maturation of DCs that had a more potent activity to stimulate T cells than immature DCs, and this effect was dependent on the expression of CD40L on LAK cells used for the stimulation of DCs. Our results seem to be consistent with a recent report in which Sato et al demonstrated that mitogen-activated $\mathrm{T}$ cells expressing CD40L promoted maturation of autologous DCs derived from healthy donors after the co-culture of both cells in vitro (8). They showed that activated DCs induced enhanced production of IL-12 that could be blocked by an anti-CD40L mAb treatment. They also showed that $70-90 \%$ of $\mathrm{T}$ lymphocytes activated with phytohemagglutinin and ionomycin expressed CD40L and these activated cells efficiently induced DC maturation. In contrast to this report, LAK cells in our culture system expressed at most only $24 \%$ of CD40L even after stimulation with anti-CD3 mAb and IL-2 (Table I). This may be attributed to the difference of methods of activation or to the difference of donor populations (healthy vs advanced cancer patients). Nevertheless, substantial amount of $\mathrm{CD}^{+} \mathrm{T}$ cells activated by anti-CD3 mAb and IL-2 expressed CD40L in our setting and contributed to DC maturation.

Importantly, our results indicated that the higher ratio of CD4/CD8 in the PBMCs before culture was associated with a higher frequency of CD40L-positive cells in LAK cells (Fig. 2). This result is consistent with the observation that the CD40Lpositive cells predominantly consist of $\mathrm{CD}^{+} \mathrm{T}$ cells (Fig. 1) and, thus, the CD4/CD8 ratio might be helpful to assume responders among the candidate patients with regard to the efficiency of DC maturation before the enrollment into this strategy. Further investigation to address whether this level of expression of CD40L would be good enough to exert DC maturation, leading to the efficient induction of anti-tumor immune responses to treat cancer in vivo is warranted. The ratio of Th1/Th2 of the LAK cells determined by the intracellular productions of IFN- $\gamma$ and IL-4 also appeared to be important to distinguish the responder from non-responder in terms of the DC maturation efficiency (Fig. 5). In this experiment, although the culture condition for the generation of LAK cells for cytokine assay differs from that for maturation of DCs, previous study suggested that the IFN- $\gamma$ production between LAK cells induced by a CD3 mAb with IL-2 and those induced by mitogens such as PMA or PHA seems to be similar in terms of cytokine production (19). Indeed, IFN- $\gamma$ has been reported to induce the differentiation of type-1 polarized DC (DC1), which is more capable of priming CTL by means of enhanced IL-12 production and up-regulation of co-stimulatory signals $(14,15)$, and effective anti-tumor immune responses induced by DC1 have been demonstrated in an animal study $(14,16)$. These studies also implicate the possible use of DC1 for clinical settings in humans. Consistent with these reports, DCs stimulated with LAK cells that specifically produced higher amounts of IFN- $\gamma$ showed efficient up-regulation of maturation markers (Fig. 5) and the enhanced antigen-presenting capacity (Fig. 4) in the current study. However, this result suggests the importance of humoral factors, including IFN- $\gamma$, that exist in the culture and may play an important role for DC maturation besides the signaling through CD40-CD40L. Indeed, DC maturation was not completely blocked by the use of the cell culture insert to prevent cell-to-cell contact in one of two patients tested (Fig. 6a). Thus, we conclude that the humoral factors may be as important as the cell-to-cell contact with LAK cells in the culture in the current study.

In vivo observation that DCs and NK cells are rapidly recruited to the sites of inflammation supports a concept stating the importance of the link between innate and acquired immunity (17-19). NK cells have been demonstrated to activate DCs and induce their maturation and Th1-type cytokine production mediated by IFN- $\gamma$ and TNF- $\alpha$ produced by NK cells with a possible involvement of additional factors, such as CD40-40L interaction (20-22). Such DCs (DC1) that are activated by NK cells, have been shown to be resistant to tumor-related suppressive factors and thus induce Th1 and 
strong CTL responses. LAK cells are known to contain a considerable amount of CD56 cells, such as NK (CD3-/CD56+), cytolytic NK-T $(\mathrm{CNK}-\mathrm{T})\left(\mathrm{CD}^{+} / \mathrm{CD}^{+} 6^{+}\right)$and cytokine-induced killer $(\mathrm{CIK})\left(\mathrm{CD}^{+} / \mathrm{CD}^{2} 6^{+}\right)$cells $(23)$. Since the LAK cells in the present study also contained substantial amounts of CD56+ cells (data not shown), although the expression levels varied from donor to donor, it would be interesting to study the detailed phenotypic analysis on LAK cells in terms of the involvement in DC maturation in these conditions.

In conclusion, we have shown that autologous LAK cells induced by anti-CD3 mAb and IL-2 efficiently promote DC maturation in vitro. In vivo experiments using the administration of a mixture of LAK cells and antigen-loaded DCs by intranodal or intratumoral injections to induce anti-tumor immune responses in mouse models are currently underway. Although this strategy requires substantial labor for the preparation not only of DCs but also LAK cells, LAK cells, which can be generated from non-adherent cells derived from PBMCs harvested for the cell source of DCs and would be discarded normally without clinical use, can substitute the addition of recombinant cytokines needed for DC maturation. Thus, this strategy may be taken into consideration for future clinical trials of tumor immunotherapy. However, this strategy needs welldesigned culture protocol and condition so that it can comply with good clinical practice (GCP). The efficient selection of patients with an indication for this strategy and CD4/CD8 ratio or Th1/Th2 ratio of the LAK cells may also be necessary.

\section{Acknowledgements}

This study was supported in part by a 2004-2005 Grant-InAid from the Ministry of Health, Labor and Welfare, Japan (No. 16241801) (to Y.U.) and a 2004-2005 Grant-In-Aid for Scientific Resarch from the Japan Society for the Promotion of Science (No. 90332949) (to N.F.).

\section{References}

1. Banchereau $\mathrm{J}$ and Palucka AK: Dendritic cells as therapeutic vaccines against cancer. Nat Rev Immunol 5: 296-306, 2005.

2. Davis ID, Jefford M, Parente $P$ and Cebon J: Rational approaches to human cancer immunotherapy. J Leuk Biol 73: 3-29, 2003.

3. Dhodapkar MV, Steinman RM, Krasovsky J, Munz C and Bhardwaj N: Antigen-specific inhibition of effector T cell function in humans after injection of immature dendritic cells. J Exp Med 193: 233-238, 2001.

4. Thurner B, Haendle I, Roder C, Dieckmann D, Keikavoussi P, Jonuleit H, Bender A, Maczek C, Schreiner D, von den Driesch P, Brocker EB, Steinman RM, Enk A, Kampgen E and Schuler G: Vaccination with mage-3A1 peptide-pulsed mature, monocytederived dendritic cells expands specific cytotoxic $\mathrm{T}$ cells and induces regression of some metastases in advanced stage IV melanoma. J Exp Med 190: 1669-1678, 1999.

5. Dhodapkar MV, Steinman RM, Sapp M, Desai H, Fossella C, Krasovsky J, Donahoe SM, Dunbar PR, Cerundolo V, Nixon DF and Bhardwaj N: Rapid generation of broad T-cell immunity in humans after a single injection of mature dendritic cells. J Clin Invest 104: 173-180, 2005.
6. Schuler-Thurner B, Schultz ES, Berger TG, Weinlich G, Ebner S, Woerl P, Bender A, Feuerstein B, Fritsch PO, Romani N and Schuler G: Rapid induction of tumor-specific type $1 \mathrm{~T}$ helper cells in metastatic melanoma patients by vaccination with mature, cryopreserved, peptide-loaded monocyte-derived dendritic cells. J Exp Med 195: 1279-1288, 2002.

7. Jonuleit H, Kuhn U, Muller G, Steinbrink K, Paragnik L, Schmitt E, Knop J and Enk AH: Pro-inflammatory cytokines and prostaglandins induce maturation of potent immunostimulatory dendritic cells under fetal calf serum-free conditions. Eur J Immunol 27: 3135-3142, 1997.

8. Sato T, Tera M, Yasuda R, Watanabe R, Berd D, Mastrangelo MJ and Hasumi K: Combination of monocyte-derived dendritic cells and activated $\mathrm{T}$ cells which express CD40 ligand: a new approach to cancer immunotherapy. Cancer Immunol Immunother 5: 53-61, 2004.

9. Caux C, Massacrier C, Vanbervliet B, Dubois B, van Kooten C, Durand I and Banchereau J: Activation of human dendritic cells through CD40 cross-linking. J Exp Med 180: 1263-1272, 1994.

10. Cella M, Scheidegger D, Palmer-Lehmann K, Lane P, Lanzavecchia A and Alber G: Ligation of CD40 on dendritic cells triggers production of high levels of interleukin-12 and enhances T cell stimulatory capacity: T-T help via APC activation. J Exp Med 184: 747-752, 1996.

11. McLellan AD, Sorg RV, Williams LA and Hart DN: Human dendritic cells activate T lymphocytes via a CD40: CD40 liganddependent pathway. Eur J Immunol 26: 1204-1210, 1996.

12. Grimm EA, Mazumder A, Zhang HZ and Rosenberg SA: Lymphokine-activated killer cell phenomenon. Lysis of natural killer-resistant fresh solid tumor cells by interleukin 2-activated autologous human peripheral blood lymphocytes. J Exp Med 155: 1823-1841, 1982.

13. Ohkawa T, Seki S, Dobashi H, Koike Y, Habu Y, Ami K, Hiraide H and Sekine I: Systematic characterization of human CD8+ $\mathrm{T}$ cells with natural killer cell markers in comparison with natural killer cells and normal CD8+ T cells. Immunology 103: 281-290, 2001

14. Sato M, Iwakabe K, Ohta A, Sekimoto M, Nakui M, Koda T, Kimura S and Nishimura T: Functional heterogeneity among bone marrow-derived dendritic cells conditioned by $\mathrm{T}(\mathrm{h}) 1-$ and $\mathrm{T}(\mathrm{h}) 2$-biasing cytokines for the generation of allogeneic cytotoxic T lymphocytes. Int Immunol 12: 335-342, 2000.

15. Kalinski P, Giermasz A, Nakamura Y, Basse P, Storkus WJ, Kirkwood JM and Mailliard RB: Helper role of NK cells during the induction of anticancer responses by dendritic cells. Mol Immunol 42: 535-539, 2005.

16. Sato $M$, Chamoto $K$ and Nishimura T: A novel tumor-vaccine cell therapy using bone marrow-derived dendritic cell type 1 and antigen-specific Th1 cells. Int Immunol 15: 837-843, 2003.

17. Biron CA: Activation and function of natural killer cell responses during via infections. Curr Opin Immunol 9: 24-34, 1997.

18. Banchereau J and Steinman RM: Dendritic cells and the control of immunity. Nature 392: 245-252, 1998.

19. Biron CA and Brossay L: NK cells and NKT cells in innate defense against viral infections. Curr Opin Immunol 13: 458-464, 2001 .

20. Piccioli D, Sbrana S, Melandri E and Valiante NM: Contactdependent stimulation and inhibition of dendritic cells by natural killer cells. J Exp Med 195: 335-341, 2002.

21. Ferlazzo G, Tsang ML, Moretta L, Melioli G, Steinman RM and Munz C: Human dendritic cells activate resting natural killer (NK) cells and are recognized via the NKp30 receptor by activated NK cells. J Exp Med 195: 343-351, 2002.

22. Gerosa F, Baldani-Guerra B, Nisii C, Marchesini V, Carra G and Trinchieri G: Reciprocal activating interaction between natural killer cells and dendritic cells. J Exp Med 195: 327-333, 2002.

23. Oner O, Ravindranath Y and Savasan S: Mechanisms of superior anti-tumor cytotoxic response of interleukin 15-induced lymphokine-activated killer cells. J Immunother 28: 44-52, 2005. 